\title{
COMPARATIVE STRUCTURAL ANALYSIS OF FLEXIBLE PAVEMENTS USING FINITE ELEMENT METHOD
}

\author{
Ankit Gupta, Assistant Professor, Department of Civil Engineering, NIT Hamirpur, India. Email: \\ anki_ce11@yahoo.co.in \\ Abhinav Kumar, Former Graduate Student, Department of Civil Engineering, NIT Hamirpur, India. \\ Email: abhinav78@gmail.com
}

doi: 10.2478/ijpeat-2013-0005

\begin{abstract}
The evaluation of bituminous concrete mixes for their tendency to rutting has been an important research field for many years. Rutting is a major type of distress encountered in bituminous pavements. The Finite Element Method (FEM) is a numerical analysis technique to obtain various structural parameters such as stress, strain and deflection of pavement layers. The objective of this paper is to study the sensitivity of these variables in reducing the vertical surface deflections, the critical tensile strains at the bottom of the bitumen layer and the critical compressive strains on the top of subgrade using the finite element method. This study has been carried out in order to compare the performance of flexible pavement using the finite element method and KENLAYER. Vertical surface deflections in flexible pavements have always been a major concern and are used as a criterion for pavement design. It is desirable to reduce the deflections as much as possible. This paper deals with ways to reduce deflections by varying the design configuration, such as increasing the Hot Mix Asphalt (HMA) modulus, the base modulus, sub base modulus and the subgrade modulus. Another objective of the present study is to investigate the effectiveness of two different methods in reducing vertical surface deflections $\left(w_{0}\right)$ and the critical tensile strains in the bitumen layer $\left(\varepsilon_{t}\right)$ or the radial strains at the bottom layer of HMA. The finite element method was adopted to evaluate the effectiveness of the two methods and the sensitivity of various factors.
\end{abstract}

Keywords: Flexible pavement, Finite element, Vertical surface deflection, Pavement modulus, Poisson's ratio

\section{INTRODUCTION}

Structural analysis in pavements has been greatly developed since the initial studies carried out by Boussinesq in which soils were modeled as a linear-elastic material (Boussinesq, 1885). Boussinesq's theory was then extended to multilayer elastic models due to the work of Burmister (Burmister, 1945) and Schiffman (Schiffman, 1962). Rutting is caused by the accumulation of permanent deformation in all pavement layers under repetitive traffic loading.

Among the contributors of rut depth in the different pavement layers, the cumulative permanent deformation in the surface course of bituminous pavement is known to be responsible for a major portion of the final rut depth measured on the pavement surface. Thus, rutting occurs only on flexible pavements, as indicated by the permanent deformation or rut depth along the wheel paths. The width and depth of the 
rut are widely affected by structural characteristics of the pavement layers (thickness and material quality), traffic loads and environmental conditions (Huang, 1993). The numerical analysis of the pavement layer is based on the finite element method (FEM). Figure 1 represents a cross section of a basic modern pavement system, showing its major components.

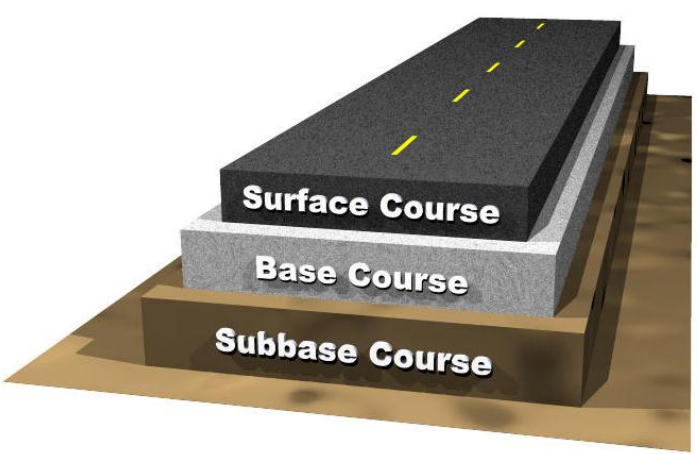

Figure 1: Basic components of a typical pavement system

This paper deals with different possible ways to reduce vertical surface deflection by varying the design configuration (input parameters), such as increasing hot mix asphalt (bitumen) modulus, the base modulus, the sub-base modulus and the subgrade modulus. The primary objective of this study is to analyze the sensitivity of the layer modulus variables in reducing the surface deflection and the soil stress in flexible pavement.

Rutting due to permanent deformation is considered one of the most serious distress mechanisms in bituminous pavements. It leads to traffic hazards by affecting vehicle steering. Furthermore, an impervious road surface will trap water, snow and ice that cause hydroplaning and loss of friction. Longitudinal cracks sometimes occur in deep ruts where they drain free water into the underlying pavement layers, thereby increasing the deterioration rate. The factors affecting permanent deformations can be divided into traffic loading, material properties and climatic conditions. Modeling is a valuable tool used for pavement design and residue assessment. The first pavement deterioration models were entirely empirical but mechanistic principles have been introduced in recent years (Gupta et al., 2014).

We have employed the ANSYS version 11 and the KENLAYER programs/software packages for the purpose of modeling and analysis of the flexible pavement subjected to repetitive wheel load. ANSYS is a finite element numerical technique and a mechanistic approach analysis, while KENLAYER is an empirical analysis technique for pavements. The finite element method, its practical application often known as finite element analysis (FEA) is a numerical technique for finding approximate solutions to Partial Differential Equations (PDE) and their systems. FEM is a special case of the more general Galerkin method with polynomial approximation functions. The solution approach is based on eliminating the spatial derivatives from the PDE. This approximates the PDE with a system of algebraic equations for steady state problems and a system of ordinary differential equations for transient problems. These equation systems are linear if the underlying PDE is linear, and vice versa. Algebraic equation systems are solved using numerical linear algebra methods. Ordinary 
differential equations that arise in transient problems are then numerically integrated using standard techniques such as the Euler's method or the Runga-Kutta method.

Premature failure in flexible pavement has long been a problem in many roads with the large increase in truck axle load. To fully utilize each pavement material in a costefficient manner, a pavement should generally have a design, striking a reasonable balance between the rutting and fatigue modes of distress. The purpose of this paper is to develop an approach for achieving an economic, balanced and quality based evaluation of the various components of the flexible pavement. The methodology is based on the damage analysis concept which has been performed to evaluate rutting on different pavement moduli and Poisson's ratio by using the ANSYS and KENLAYER programs.

There are various modes of failure of flexible pavement. Flexible pavement is constructed always bearing in mind its durability, and surface skid resistance under inservice conditions. Further it is expected to exhibit minimum possible cracking and rutting in flexible pavement layers. Large stresses and strains are produced with thicker layers carrying higher flexural stress than thinner layers, while subjected to large and more concentrated loads. The increased rutting or decreased fatigue life of the flexible pavement may be attributed to the shortcomings of the application of the flexible pavement analysis and the lack of attention to identify the pavement components which aid in achieving a balanced section which renders equal pavement lives with respect to rutting and fatigue. The use of FEM model through ANSYS allows the model to accommodate the load dependent stiffness of the granular and subgrade materials, although most of the models still use linear elastic theory as constitutive relationship.

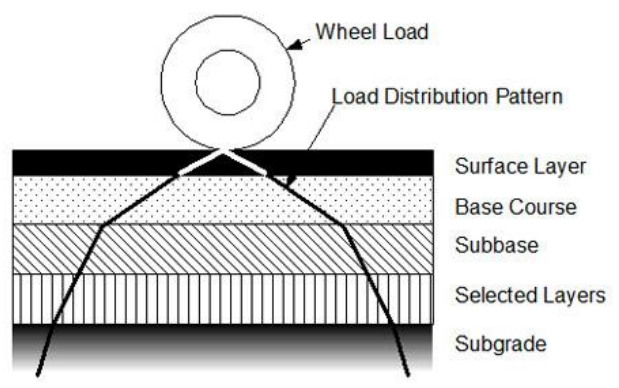

Figure 2: Load distribution along various layers

In the analysis of flexible pavement, axle loads on the surface of the pavement produce two different types of strains which are believed to be most critical for design purposes. These are the horizontal tensile strains; $\varepsilon_{\mathrm{t}}$ at the bottom of the bitumen layer, and the vertical compressive strain; $\varepsilon_{\mathrm{c}}$ at the top of the subgrade layer. If the horizontal tensile strain $\varepsilon_{t}$ is excessive, cracking of the surface layer will occur and the pavement will fail due to fatigue. If the vertical compressive strain $\varepsilon_{\mathrm{c}}$ is excessive, permanent deformations are observed at the surface of the pavement structure (from overloading the subgrade) and pavement fails due to rutting. 


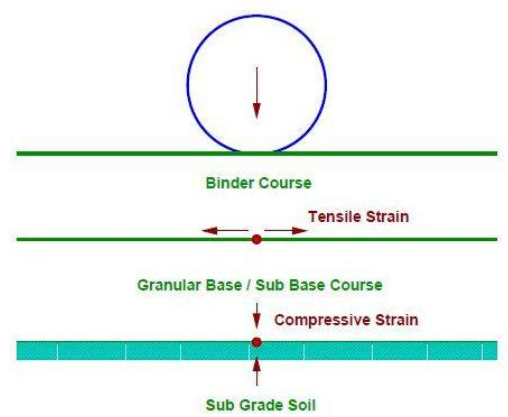

Figure 3: Failure modes and critical strains

\subsection{Rutting Failure Criteria}

The relationship between rutting failure and compressive strain at the top of subgrade material has been investigated and definitions suggested by various institutions, organizations and individual researchers depending upon the varying load application and pavement material characteristics. The present study employs a model suggested by the Asphalt Institute (Asphalt Institute, 1982), which can be stated as follows:

$\mathrm{Nr}=1.365 \times 10-9(1 / \varepsilon \mathrm{c}) 4.477$

where

$\mathrm{N}_{\mathrm{r}}=$ number of load repetitions to limit rutting

$\varepsilon_{\mathrm{c}}=$ vertical compressive strain at the top of the subgrade

\section{LITERATURE REVIEW}

Abed and Al-Azzawi (2012) concluded that the stress level decreased by $14 \%$ in the leveling course and $27 \%$ in the base course, while the rut depth increased by $12 \%$ and $28 \%$ in those respective layers because the material properties had been changed. The modulus of elasticity for surface layer was taken as $2689 \mathrm{~N} / \mathrm{mm}^{2}$ whereas for base course was taken as $1655 \mathrm{~N} / \mathrm{mm}^{2}$. Oscarsson and Popescu (2011) concluded that the results from the semi-rigid pavement section indicated that shear stress and elastic shear strain may be difficult to relate to flow rutting in very stiff pavement sections.

\section{METHODOLGY}

A typical cross section consists of a bituminous layer with thickness $\mathrm{d}_{1}=100 \mathrm{~mm}$ and elastic modulus of $\mathrm{E}_{1}=229.8 \mathrm{MPa}$, a base layer with thickness $\mathrm{d}_{2}=300 \mathrm{~mm}$ and elastic modulus $E_{2}=114.9 \mathrm{MPa}$, and a sub base layer with thickness $\mathrm{d}_{3}=300 \mathrm{~mm}$ and elastic modulus $\mathrm{E}_{3}=46 \mathrm{MPa}$, resting on a subgrade with modulus of elasticity $\mathrm{E}_{4}=$ 5.74 MPa. This is regarded as a section with reference components. Different likely cross sections that may be used in Indian Roads are considered for analysis through varying the reference components. In other words, $\mathrm{E}_{1}$ is varied from 229.8 to 1149 $\mathrm{MPa}$, while $\mathrm{E}_{2}$ from 114.9 to $1200 \mathrm{MPa}$ and $\mathrm{E}_{3}$ from 46 to $1100 \mathrm{MPa}$ and $\mathrm{E}_{4}$ from 5.74 to $200 \mathrm{MPa}$. Materials in each layer are characterized by a modulus of elasticity (E) and a Poisson's ratio (v). Poisson's ratio (v), the values of 0.35, 0.30, 0.30 and 0.40 are considered for bituminous layer, base course, sub base layer and subgrade, respectively. Traffic is expressed in terms of repetitions of single axle load 18-kip 
applied to the pavement on two sets of dual tires. The studied contact pressure is 0.70 $\mathrm{MPa}$. The dual tire is approximated by two circular plates with a radius of $100 \mathrm{~mm}$ and spaced at $350 \mathrm{~mm}$ center to center. The detrimental effects of axle load and tire pressure on various pavement sections are examined by computing the tensile strain $\left(\varepsilon_{t}\right)$ at the bottom of the bituminous layer and the compressive strain $\left(\varepsilon_{\mathrm{c}}\right)$ at the top of the subgrade. Subsequently a damage analysis is carried out using the two critical strains to compute pavement life for permanent deformation (rutting). A sensitivity analysis demonstrates the effect of various parameters on flexible pavement. The analysis is performed using the finite element computer package ANSYS. The results indicate that displacements under loading are the closest to mechanistic methods. A research study is then undertaken to incorporate the realistic material properties of the pavement layers and the moving traffic load, in the analysis of the flexible pavement, employing the FEM. For comparison purposes, a flexible pavement is conventionally taken as a multilayered elastic system in the analysis of pavement response, using KENLAYER.

As with models for the prediction of resilient response, there are a large number of models that have been proposed to represent the Permanent Deformation (PD) of granular materials. These models appear to be either based on observed performance or are expressed as a function of the number of load applications/cycles and the applied stress state. Duncan and Chang (1970) proposed a hyperbolic model for predicting plastic strains from triaxial tests as a function of confining and deviator stresses, cohesion, the angle of internal friction and a ratio of compressive strength to an asymptotic stress difference. Well-known geotechnical models of this type are the Cam-Clay (Schofield and Wroth, 1968) and Drucker-Prager (Drucker and Prager, 1952) models. The Mechano-Lattice (ML) method of analysis (Yandell, 1971), determines the elastic and plastic response of the system, as a wheel rolls across the surface of the model. The pavement structure is modeled as a series of springs in a lattice framework. The observation that, after repeated load triaxial testing that materials have a higher secant modulus on unloading than loading is used to develop the plastic strains within the structure. The plastic strains predicted by the ML method are comparable to the measured plastic strains/ruts. Table 1 shows the typical pavement material properties. The material properties are shown on Table 2. A total of 17 cases were analyzed. The finite element mesh is shown on Figure 4. This analysis is based on the assumption that all layers are linearly elastic, although HMA layers are viscoelastic and base layers are nonlinear elastics. Analysis of the pavement model in ANSYS has been carried out with the help of the Drucker-Prager method and regular hexagonal meshing has been used in order to analyze the pavement model at every tiny, infinitesimal element.

As far as the boundary conditions of the pavement are concerned, the subgrade layer has its displacements completely restrained. The sides of the pavement model have no restraints in vertical direction but they are completely restrained over the other two possible displacements, as illustrated on Figure 5. The procedure is performed once the tires have been placed on the bituminous surface. In the contact discretization, the bituminous surface is defined as the master surface, whereas the tire surfaces in contact with the bituminous surface are defined as slave surfaces. Subsequently the simulation is performed and in the equilibrium configuration the results lead to the correct phenomenon. 


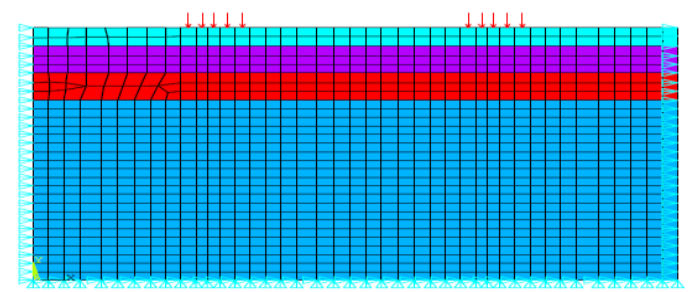

Figure 4: Loading arrangement and meshing

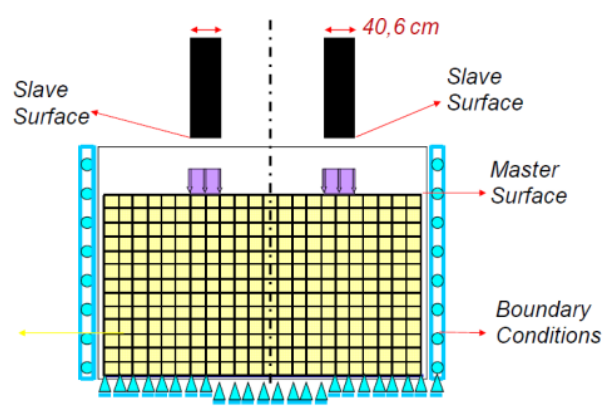

Figure 5: Boundary condition

Table 1: Pavement material properties

\begin{tabular}{|c|c|c|c|}
\hline Material & E (MPa) & Poisson's ratio & Unit weight $\mathbf{( K g / \mathbf { m } ^ { 3 } )}$ \\
\hline Bituminous surface & 229.8 & 0.35 & 2400 \\
\hline Soil aggregate base layer & 114.9 & 0.30 & 2300 \\
\hline Sub base layer & 46 & 0.30 & 2250 \\
\hline Subgrade layer & 5.74 & 0.40 & 1800 \\
\hline
\end{tabular}

Table 2: Pavement material modulus range used in analysis

\begin{tabular}{|c|c|c|}
\hline Material & E (MPa) & Poisson's ratio \\
\hline Bituminous surface & 229.8 to 1149 & 0.35 \\
\hline Soil aggregate base layer & 114.9 to 1200 & 0.30 \\
\hline Sub base layer & 46 to 1100 & 0.30 \\
\hline Subgrade layer & 5.74 to 200 & 0.40 \\
\hline
\end{tabular}

\section{EFFECT OF LAYER MODULUS}

This study has been carried out in order to compare flexible pavement performance using FEM and KENLAYER computer programs, respectively. Comparison of the output has been made to determine the governing distress and deterioration models. Table 3 shows the variation of input parameters in the analysis and Figures 6-9 shows the comparative contour plot for the vertical strain of FEM and KENLAYER, respectively. As observed on Figures 6-9, the vertical deflection reduces as the modulus increases at all values of E. It is also noteworthy that, $w_{0}$ exhibits no sensitivity with respect to the variation of $E_{1}$, as opposed to $E_{2}, E_{3}$ and $E_{4}$. The investigated pavement components are elasticity moduli $\left(\mathrm{E}_{1}, \mathrm{E}_{2}, \mathrm{E}_{3}\right.$ and $\left.\mathrm{E}_{4}\right)$ for the bituminous layer, base layer, sub base layer and the subgrade elasticity modulus, respectively. The results of pavement analysis showed that $\mathrm{E}_{4}$ are the key elements which control the equilibrium between fatigue and rutting lives $\left(\mathrm{N}_{f}\right.$ and $\mathrm{N}_{\mathrm{r}}$, respectively). This is the case because increasing $\mathrm{E}_{4}$ sharply increases $\mathrm{N}_{\mathrm{r}}$, and does not affect $\mathrm{N}_{\mathrm{f}}$. The study also concluded that by increasing $\mathrm{E}_{3}, \mathrm{E}_{2}$ and $\mathrm{E}_{1}, \mathrm{~N}_{\mathrm{f}}$ and $\mathrm{N}_{\mathrm{r}}$ mildly increase. Therefore, it may be stated that $\mathrm{E}_{4}$ is the most effective component in 
pavement structure for increasing pavement life, followed by $\mathrm{E}_{3}$ (high-quality subbase).

Table 3: Variation of input parameters in analysis

\begin{tabular}{|c|c|c|c|c|}
\hline $\mathbf{C A S E}$ & $\mathbf{E}_{\mathbf{1}}(\mathbf{P a})$ & $\left.\mathbf{E}_{\mathbf{2}} \mathbf{( P a}\right)$ & $\mathbf{E}_{\mathbf{3}}(\mathbf{P a})$ & $\mathbf{E}_{\mathbf{4}}(\mathbf{P a})$ \\
\hline 1 & 229800,000 & 114900,000 & 45960,000 & 5745,000 \\
\hline 2 & 459600,000 & 114900,000 & 45960,000 & 5745,000 \\
\hline 3 & 689400,000 & 114900,000 & 45960,000 & 5745,000 \\
\hline 4 & 919200,000 & 114900,000 & 45960,000 & 5745,000 \\
\hline 5 & 1149000,000 & 114900,000 & 45960,000 & 5745,000 \\
\hline 6 & 229800,000 & 229800,000 & 45960,000 & 5745,000 \\
\hline 7 & 229800,000 & 344700,000 & 45960,000 & 5745,000 \\
\hline 8 & 229800,000 & 459600,000 & 45960,000 & 5745,000 \\
\hline 9 & 229800,000 & 850000,000 & 45960,000 & 5745,000 \\
\hline 10 & 229800,000 & 1200000,000 & 45960,000 & 5745,000 \\
\hline 11 & 229800,000 & 114900,000 & 91920,000 & 5745,000 \\
\hline 12 & 229800,000 & 114900,000 & 183840,000 & 5745,000 \\
\hline 13 & 229800,000 & 114900,000 & 1100000,000 & 5745,000 \\
\hline 14 & 229800,000 & 114900,000 & 45960,000 & 17235,000 \\
\hline 15 & 229800,000 & 114900,000 & 45960,000 & 34470,000 \\
\hline 16 & 229800,000 & 114900,000 & 45960,000 & 68940,000 \\
\hline 17 & 229800,000 & 114900,000 & 45960,000 & 200000,000 \\
\hline
\end{tabular}

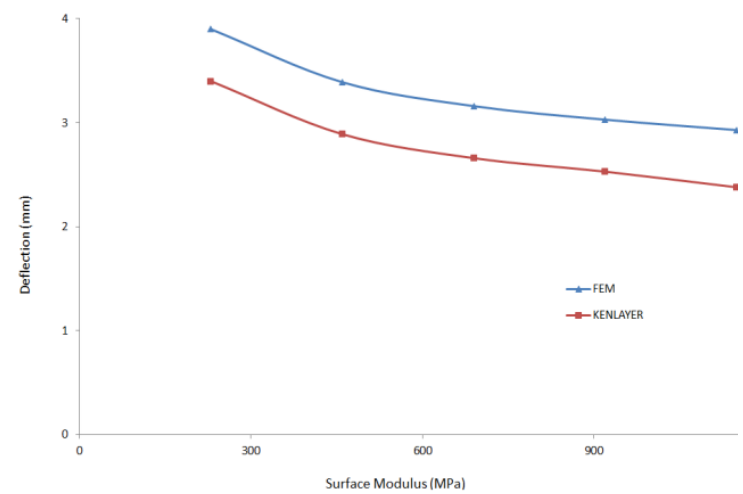

Figure 6: Effect of surface modulus on vertical deflection

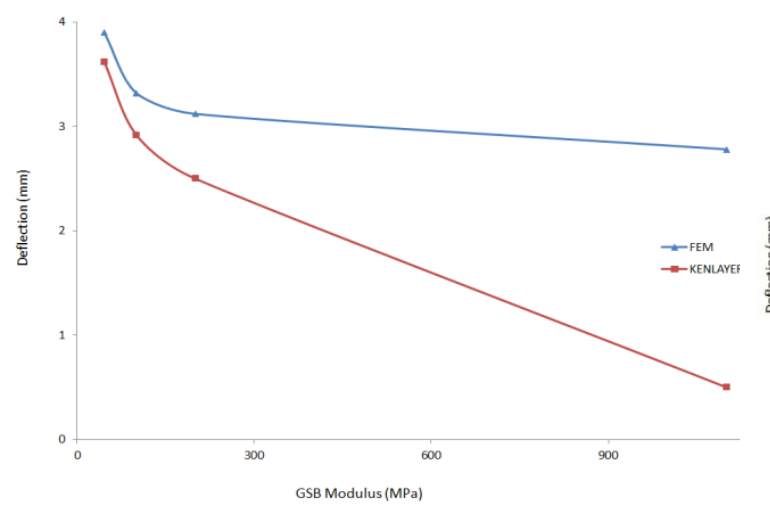

Figure 8: Effect of GSB modulus on vertical deflection

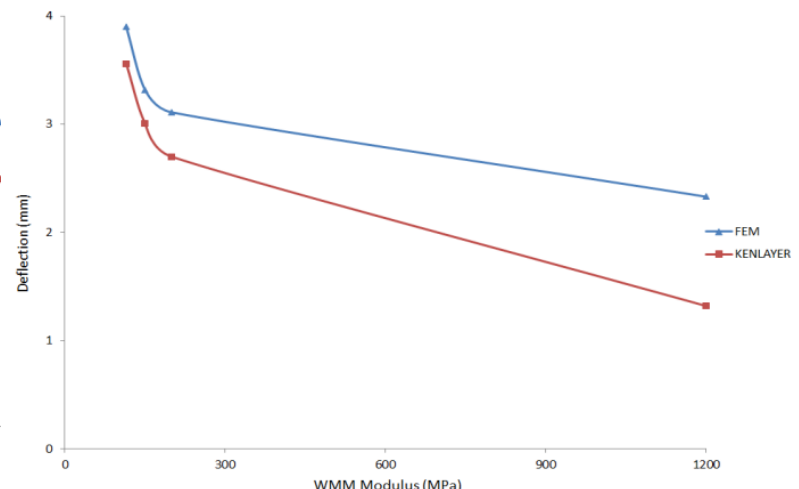

Figure 7: Effect of WMM modulus on vertical deflection

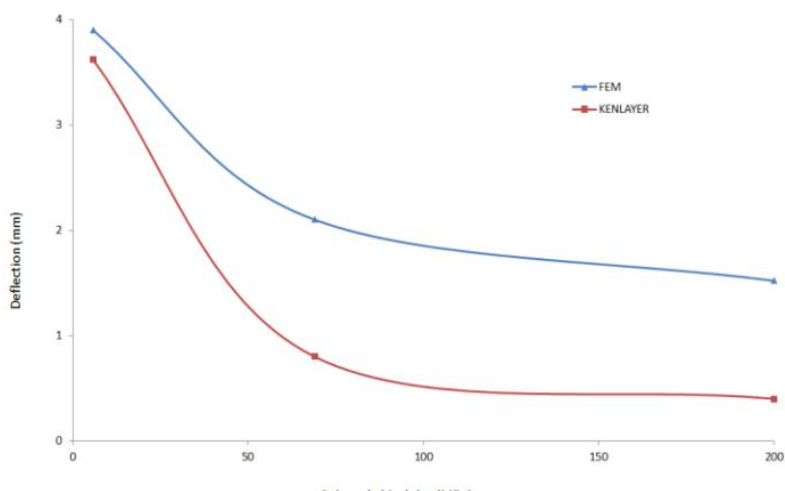

Figure 9: Effect of subgrade modulus on vertical deflection 


\section{CONCLUSIONS}

- KENLAYER can be used to predict the performance of flexible pavement more easily and efficiently since it is more user-friendly.

- Subgrade modulus is the key element which controls the excess vertical surface deflection in flexible pavement. Hence, more efforts are required for achieving high value of subgrade modulus as compared to other top layers of pavement.

- Base course and surface layer modulus have minor effects on the excess vertical surface deflection in flexible pavement.

- The design obtained from FEM and KENLAYER analysis is different for the corresponding modulus. However, there are discrepancies in the results obtained from the KENLAYER program. Although the pavement structure was assumed to be linear elastic, calculated maximum vertical deflections are lower than the corresponding results obtained from FEM analysis. 


\section{REFERENCES}

Abed, A.H., and Al-Azzawi, A.A. (2012), "Evaluation of Rutting Depth in Flexible Pavements by Using Finite Element Analysis and Local Empirical Model", American Journal of Engineering and Applied Sciences, Vol. 5, No. 2, pp. 163-169.

Asphalt Institute (1982). Research and Development of Asphalt Institute's Thickness Design Manual. $9^{\text {th }}$ Ed., Research Report 82-2, The Asphalt Institute.

Boussinesq, J. (1885), “Application des potentiels á l'étude de l'équilibre et du movement des solidesélastique", Paris: Gauthier-Villard.

Burmister, D.M. (1945), "The General Theory of Stresses and Displacements in Layered Soil Systems", Journal of Applied Physics. Vol. 16, pp. 89-94, 126-127, 296302.

Duncan, J.M., and Chang, C.Y., (1970), "Nonlinear Analysis of Stress and Strain in Soils", ASCE Journal of Soil Mechanics and Foundations Division, 96 (SM5), pp. 1629-1653.

Drucker D.C., and Prager, W., (1952), "Soil Mechanics and Plastic Analysis of Limit Design", Quarterly, Applied Mathematics, Vol.10, No.2, pp. 157-164.

Gupta, A., Kumar, P., and Rastogi, R. (2014), "Critical Review of Flexible Pavement Performance Models", Korean Society of Civil Engineers (KSCE), Journal of Civil Engineering, Springer, Vol. 18, No. 1, pp. 142-148.

Huang Y.H., (1993), "Pavement Analysis and Design", Englewood Cliffs, New Jersey, Prentice-Hall.

Oscarsson, E., and Popescu, L., (2011), "Evaluation of the CalME Permanent Deformation Model for Asphalt Concrete Layers", International Journal of Pavement Research Technology, Vol. 4, No. 1, pp. 21-33.

Schiffman, R.L. (1962), "General Solution of Stresses and Displacements in Layered Elastic Systems", Proceeding of International Conference on the Structural Design of Asphalt Pavement, University of Michigan, Ann Arbor, Michigan, USA.

Schofield, A.N., and Wroth, C.P., (1968), Critical State Soil Mechanics, McGraw Hill, London.

Yandell, W.O. (1971), "Prediction of the Behavior of Elastoplastic Roads During Repeated Rolling Using the Mechano-Lattice Analogy", Highway Research Record, Highway Research Board, No. 374, pp. 29-41. 